\title{
Field independence and input grouping in free recall
}

\author{
JOHN H. MUELLER and DONNA M. FISHER \\ University of Missouri, Columbia, Missouri 65211
}

\begin{abstract}
High and low scorers on the Hidden Figures Test were compared on a free recall task that involved word triads having both an associative and a rhyming relationship. The words were presented either one at a time or in a simultaneous display, with the triad members either blocked or randomly arranged in the input sequence. Field independence had little effect on total recall, and any effect on organization seemed to favor field-dependent subjects.
\end{abstract}

Field independence has been characterized as the ability to overcome perceptual context effects by using an internal frame of reference rather than the external context (cf. Davis \& Frank, 1979; Goodenough, 1976). In contrast, field dependence occurs when the organization of the external field is accepted as a given and used without modification. Field dependence is generally accompanied by a more global, passive, and intuitive approach to learning, with particular attention to social cues. In contrast, field-independent people tend to be more active participants in a learning task, restructuring the external frame of reference and generating organization when it is not readily apparent.

Previous research has led to the conclusion that field independence may not affect the amount recalled as much as it affects organizational strategies (Goodenough, 1976). For example, Fleming (cited by Goodenough, 1976) compared field-dependent and -independent subjects on a word list that could be hierarchically structured. Field-dependent subjects did worse than field-independent subjects when the words were presented in a subordinate-to-superordinate sequence (e.g., man, vertebrate, animal), but there was no difference with the reverse order. Presumably, early presentation of a subordinate provided no initial external structure, so field-dependent subjects suffered relative to the fieldindependent subjects, who generate their own internal structure, whereas early presentation of the superordinate provided organization for the items to follow for both field-dependent and -independent subjects alike.

The present experiment examined how grouping related items in input affected recall of field-dependent and field-independent subjects. Generally speaking, recall and clustering are enhanced when related items are presented together, compared with random presentation. If field-independent subjects ignore external

Requests for reprints should be sent to John Mueller, Psychology Department, 210 McAlester Hall, University of Missouri, Columbia, Missouri 65211. Helpful comments on an earlier draft were provided by Carl Bennink and Ronald Schmeck. field constraints, they should be less affected by the blocked-random manipulation than are field-dependent subjects, whereas field-dependent subjects would presumably be more reliant on spatial-temporal contiguity as a basis for grouping items.

The blocking aspect was our major interest, but we examined this factor for two modes of presentation and two types of intralist relationships. First, single-item presentation was compared with whole-list (simultaneous) arrays. Field-dependence differences should be more apparent with whole-list presentation, as fieldindependent subjects could more readily scan the display to restructure it. Second, a rhyming relationship (e.g., WISH-DISH) was compared with an associative relationship (e.g., HOPE-WISH) to explore field-dependence differences in level of processing (Craik, 1977). Because the rhyme and associate derive from a common base word, subjects could in fact recall the whole triad together, reflecting an elaborative encoding strategy. Field-independent subjects should show more elaboration, since using both types of relationships simultaneously involves even more restructuring than merely clustering on one or the other basis alone.

\section{METHOD}

\section{Subjects}

The 72 subjects were recruited from a pool of introductory psychology students who had completed the Hidden Figures Test (French, Ekstrom, \& Price, 1963). High scorers had scores above 12, and low scorers had scores below 8 . Subjects were assigned to the eight groups formed by the factorial combination of field dependence (high, low), mode of presentation (single item, whole list), and order (blocked, random).

\footnotetext{
Materials

The 12 triads were each composed of a base word, a rhyme, and an associate (e.g., FAST-LAST-QUICK), for which the base-associate and base-rhyme relationships were equated in strength. ${ }^{\prime}$ The words were presented either simultaneously or sequentially (single-item display). Triad members were either blocked together or separated by other items. In the whole-list display, triads were shown in two columns of six triads each, with the base word in the middle (rhymes to the right and left equally often). In single-item presentation, the rhyme preceded
} 
and followed the base word equally of ten. Four orders were constructed, counterbalancing rhyme and associate locations, and a different order was used for each study trial.

\section{Procedure}

The first phase involved four study-test trials, with the 36 items shown for study at a rate that allowed $2 \mathrm{sec} /$ word, followed by a 2-min written recall test. Trial 4 was followed by the forward and backward digit-span tests from the WAIS. An unannounced delayed recall test followed the digit-span tests, without further study. Subjects then completed the StateTrait Anxiety Inventory (Spielberger, Gorsuch, \& Lushene, 1970) and Inventory of Learning Processes (Schmeck, Ribich, \& Ramanaiah, 1977).

\section{RESULTS}

\section{Immediate Recall}

Table 1 summarized recall performance. Effects described as significant involve $\mathrm{p}<.05$. Because order and mode produce known effects, these factors will be discussed in detail only for interactions with field independence.

Whole-list presentation led to greater recall of rhymes, associates, and base words (Fs $>3.79$ ), and blocking led to superior recall of all three types of words (Fs $>14.22$ ). The only interaction of Mode by Order was for base-word recall $[F(1,64)=5.46$, MSe $=6.48]$, as the blocking advantage was more apparent with whole-list arrays. Field independence was not a significant main effect for any of the three word types $(\mathrm{Fs}<1)$, nor did it interact with mode or order alone or

Table 1

Average Recall and Organization on the Immediate Tests by Input Order, Hidden Figures Test Score, and Display Mode

\begin{tabular}{|c|c|c|c|c|}
\hline & \multicolumn{2}{|c|}{ Blocked } & \multicolumn{2}{|c|}{ Random } \\
\hline & High & Low & High & Low \\
\hline & \multicolumn{4}{|c|}{ Single-Item Presentation } \\
\hline \multicolumn{5}{|l|}{ Recall } \\
\hline Rhymes & 7.53 & 7.50 & 6.86 & 6.22 \\
\hline Associates & 8.06 & 7.92 & 7.42 & 6.72 \\
\hline Base Words & 8.25 & 8.53 & 8.14 & 7.14 \\
\hline \multicolumn{5}{|l|}{ Clusters } \\
\hline Rhymes & 6.56 & 5.94 & 4.64 & 4.44 \\
\hline Associates & 5.14 & 5.94 & 2.31 & 1.72 \\
\hline \multicolumn{5}{|l|}{ Triads } \\
\hline Consecutive & .62 & .57 & .16 & .17 \\
\hline \multirow[t]{2}{*}{ Anywhere } & .77 & .73 & .51 & .49 \\
\hline & \multicolumn{4}{|c|}{ Whole-List Presentation } \\
\hline \multicolumn{5}{|l|}{ Recall } \\
\hline Rhymes & 7.33 & 7.06 & 5.64 & 5.31 \\
\hline Associates & 7.17 & 6.92 & 5.47 & 5.50 \\
\hline Base Words & 7.86 & 7.53 & 5.61 & 5.47 \\
\hline \multicolumn{5}{|l|}{ Clusters } \\
\hline Rhymes & 5.64 & 5.97 & 2.72 & 2.50 \\
\hline Associates & 5.00 & 4.38 & 1.14 & 1.47 \\
\hline \multicolumn{5}{|l|}{ Triads } \\
\hline Consecutive & .61 & .66 & .07 & .10 \\
\hline Anywhere & .77 & .74 & .35 & .30 \\
\hline
\end{tabular}

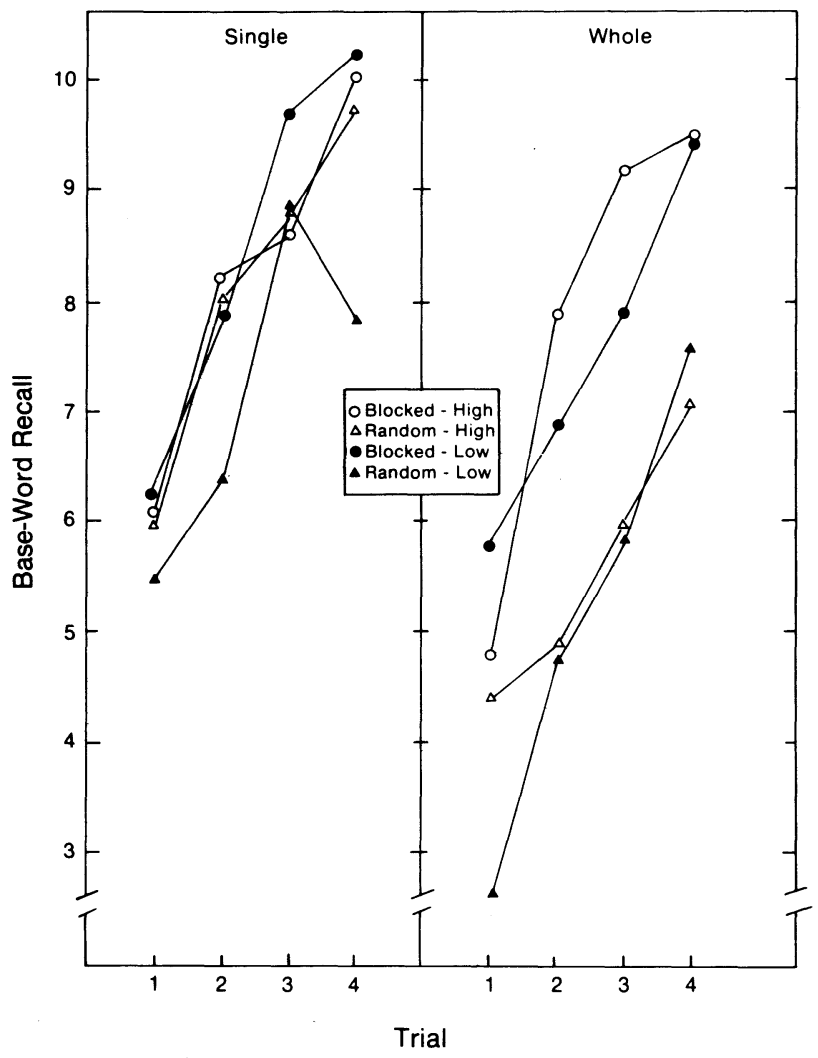

Figure 1. Base-word recall by mode of presentation for each input order (blocked, random) and field-independence combination (high or low on the Hidden Figures Test).

jointly $(F s<1.50)$. The only other significant effect was the four-way interaction of Mode by Order by Field by Trials for base-word recall $[\mathrm{F}(3,192)=4.75$, $\mathrm{MSe}=1.67]$ (Figure 1). With single-item presentation, field-independent subjects showed no blocked-random effect, whereas blocking helped field-dependent subjects. With whole-list arrays, blocking helped field-dependent subjects on all trials and eventually helped field-independent subjects, but not initially.

Both types of clusters revealed significant mode (Fs $>5.72)$ and order (Fs > 33.95) main effects, with no interaction $(F s<3.12)$. Field independence was not a significant main effect for either type of clustering $(F s<1)$, nor did it interact with mode or order, alone or jointly (Fs $<3.22)$. The Mode by Order by Field interaction was marginally significant for associate clusters $[F(1,64)=3.22, \mathrm{MSe}=7.62, \mathrm{p}<.08]$. Blocking improved clustering more for field-dependent subjects with single-item presentation, compared with fieldindependent subjects, whereas blocking with whole-list displays improved clustering more for field-independent subjects. The Order by Field by Trials interaction was significant for rhyme clusters $[\mathrm{F}(3,192)=3.53, \mathrm{MSe}=$ 2.67]. For random presentation, field-dependent subjects recalled fewer rhyme clusters on Trials 1-2, and then they surpassed field-independent subjects on 
Trials 34. When triad members were blocked in input, field-dependent subjects had more rhyme clusters on Trial 1, fewer on Trials 2-3, then more again on Trial 4. Thus by Trial 4, field-dependent subjects were clustering rhymes more regardless of blocking, although initially, they showed less such clustering than did field-independent subjects.

Triad recall was first scored by a strict criterion, under which all three members had to appear consecutively in output (in no particular order within the triad), then by a lenient criterion, under which the three members could be anywhere in output, even separated by members of other triads. (The values shown in Table 1 are the number of triads divided by the number of base words.) The strict scoring revealed no mode or field main effects $(\mathrm{Fs}<1)$, but blocking did increase whole-triad recall $[\mathrm{F}(1,64)=126.24$, MSe $=.138]$. The Order by Trial interaction indicated a greater increase over trials with blocked input $[\mathrm{F}(3,192)=15.40, \mathrm{MSe}=$ .023]. The only other significant effect was a Mode by Field by Trials interaction $[\mathrm{F}(3,192)=3.14, \mathrm{MSe}=$ .023] , as shown in Figure 2. With whole-list displays, field-dependent subjects recalled fewer intact triads than did field-independent subjects on Trial 1, but

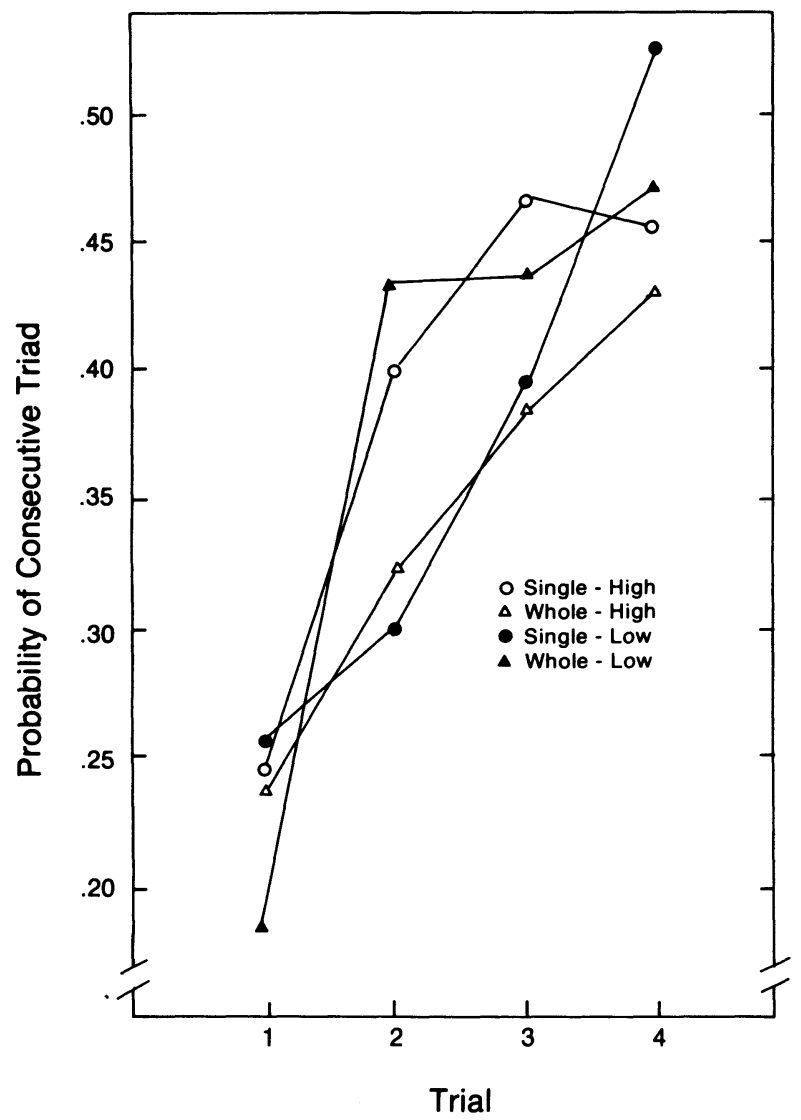

Figure 2. Triad recall by field independence (high or low on the Hidden Figures Test) and mode of presentation (single item, whole list).
Table 2

Correlations Between Recall Performance (Trials 1-4) and Subscales of the Inventory of Learning Processes, State Anxiety, and Test Anxiety

\begin{tabular}{|c|c|c|c|c|c|c|c|}
\hline & \multicolumn{4}{|c|}{ ILP } & \multicolumn{3}{|c|}{ Anxiety } \\
\hline & Sy & $\mathrm{El}$ & $\mathrm{F}$ & $\mathbf{M}$ & $S$ & W & $\mathrm{E}$ \\
\hline & \multicolumn{7}{|c|}{ Recall } \\
\hline Rhyme & 10 & $24 *$ & 03 & 14 & -01 & 05 & 12 \\
\hline Associate & 02 & 14 & 07 & 11 & -06 & -02 & 09 \\
\hline Base & 19 & 22 & 12 & 17 & -13 & -06 & 03 \\
\hline \multirow[t]{2}{*}{ Total } & 12 & 22 & 08 & 15 & -07 & -01 & 09 \\
\hline & \multicolumn{7}{|c|}{ Clusters } \\
\hline Rhyme & 17 & $24 *$ & 09 & $23 *$ & -09 & -03 & 01 \\
\hline \multirow[t]{2}{*}{ Associate } & 15 & 20 & 13 & $23^{*}$ & -18 & -06 & -01 \\
\hline & \multicolumn{7}{|c|}{ Triads } \\
\hline Consecutive & 10 & 17 & 16 & $28 *$ & -12 & 02 & 02 \\
\hline Anywhere & 01 & 12 & 12 & $26 *$ & -06 & 03 & 04 \\
\hline
\end{tabular}

Note-Sy = synthesis, $E L=$ elaboration, $F=$ fact,$M=$ method; $S=$ state,$W=$ worry, $E=$ emotion. Worry and emotion are subscales of the Test Anxiety Inventory. $\quad * p<.05$.

thereafter, field-dependent subjects recalled more triads. With single-item presentation, the field-dependent subjects eventually surpassed field-independent subjects, but only after three trials.

The lenient triad scoring revealed significant main effects for mode and order [Fs $(1,64)=5.55$ and 90.35] and a Mode by Order interaction $[F(1,64)=6.32$, Mse = $.091]$, as blocking produced equal levels of whole-triad recall for both modes, whereas random presentation led to more recall with single-item than with whole-list presentation. The field-independence main effect was not significant $(F<1)$, nor did it interact with any other effects $(\mathrm{Fs}<1.36)$.

\section{Delayed Recall}

The final recall results can be summarized very briefly. The blocking advantage was significant for every measure, but only two other effects were significant. First, single-item presentation led to more associative clustering $[F(1,64)=5.26]$. Second, the Mode by Field interaction for rhyme clustering $[\mathrm{F}(1,64)=4.41]$ showed that field-independent subjects clustered more rhymes than did field-dependent subjects with singleitem input (means $=8.0$ and 6.4), whereas this was reversed with whole-list presentation (means $=5.7$ and $6.8)$.

\section{Other Individual Differences Analyses}

Table 2 presents correlations among the subscales of the Inventory of Learning Process (ILP) (Schmeck et al., 1977), the State-Trait Anxiety Inventory (Spielberger et al., 1970), and recall. Scores on the Test Anxiety Inventory (Spielberger, 1980) were also available and were included in these analyses. The method subscale of the ILP was somewhat more correlated with organization measures than with recall, and the elabora- 
tion subscale was moderatley correlated with recall. Anxiety was not correlated with recall, perhaps due to a restricted range of scores.

\section{DISCUSSION}

These data essentially reproduced the expected effects for mode and blocking, although it is a little surprising that rhyme clusters were at least as numerous as associate clusters. Overall, the results are consistent with the general expectation that field independence has a greater effect on organization than on the amount actually retrieved. The only significant recall effect involving field independence was the complex interaction for base-word recall (Figure 1). Only field-dependent subjects had depressed recall with random single-item presentation, whereas random presentation was detrimental to both fielddependent and -independent subjects with whole-list arrays. In terms of organization, field-dependent subjects seemed to show more organization than did field-independent subjects, at least on the later trials (e.g., Figure 2, and rhyme clusters), just the reverse of initial expectations.

It appears that while field independence may result in greater organization in some cases, the result may depend on just how organization is defined. While conventional enough, the present definition is different from that used by Fleming (cited by Goodenough, 1976). It is possible that the relationships here were too obvious for differences to emerge, or too limited in that only pairwise connections were involved. Another possibility is that the study time was too long, masking any differences. Alternatively, it may be that the index of field independence is involved (cf. Widiger, Knudson, \& Rorer, 1980). Whereas the Hidden Figures Test measures the ability to differentiate a part from a whole, elaborative organization is actually the reverse in a sense (i.e., creating a whole from parts). In any event, the conclusion that field independence leads to more organized recall seems to require further qualification.

\section{REFERENCES}

Craik, F. I. M. Depth of processing in recall and recognition. In S. Dornic (Ed.), Attention and performance (Vol. 6). Hillsdale, N.J: Erlbaum, 1977.

Davis, J. K., \& Frank, B. M. Learning and memory of field independent-dependent individuals. Journal of Research in Personality, 1979, 13, 469-479.

French, J. W., Ekstrom, R. B., \& Price, L. A. Kit of reference tests for cognitive factors. Princeton, N.J: Educational Testing Service, 1963.

Goodenough, D. R. The role of individual differences in field dependence as a factor in learning and memory. Psychological Bulletin, 1976, 83, 675-694.

Schmeck, R. R., Ribich, F., \& Ramanaiah, N. Development of a self-report inventory for assessing individual differences in learning processes. Applied Psychological Measurement, 1977, 1, 413-431.

Spielberger, C. D. Preliminary manual for the Test Anxiety Inventory. Palo Alto, Calif: Consulting Psychologists Press, 1980.

Spielberger, C. D., Gorsuch, R. L., \& Lushene, R. E. Manual for the State-Trait Anxiety Inventory. Palo Alto, Calif: Consulting Psychologists Press, 1970.

Widiger, T. A., Knudson, R. M., \& Rorer, L. G. Convergent and discriminant validity of measures of cognitive styles. Journal of Personality and Social Psychology, 1980, 39, 116-129.

\section{NOTE}

1. The authors wish to thank David Brooks for providing a copy of the normative material.

(Received for publication October 22, 1980.) 